\title{
Stent placement for vertebral artery occlusive disease: preliminary clinical experience
}

\author{
Richard D. Fessler, M.D., Ajay K. Wakhloo, M.D., Ph.D., Giuseppe Lanzino, M.D., Adnan I. \\ Qureshi, M.D., Lee R. Guterman, Ph.D., M.D., and L. Nelson Hopkins, M.D.
}

Department of Neurosurgery and Toshiba Stroke Research Center, School of Medicine and Biomedical Sciences, State University of New York at Buffalo, Buffalo, New York

Symptoms of vertebrobasilar insufficiency may precede neurological sequelae in up to $50 \%$ of patients. Although select patients may benefit from microsurgical revascularization, combined perioperative morbidity and mortality rates can be as high as $20 \%$. The authors present their preliminary clinical experience using stent placement for symptomatic vertebral artery (VA) occlusive disease.

Six patients with clinical symptoms of vertebrobasilar insufficiency in whom VA stents were placed from 1995 to 1998 were identified. Diagnostic four-vessel cerebral angiography identified causative stenotic, atherosclerotic lesions in all cases. A transfemoral or transradial artery approach after the patient had undergone full heparinization was chosen for endovascular stenting. Guidewire placement across the lesion followed by urokinase infusion preceded stenting. Prestent angioplasty was performed in two patients. Following the procedure, all patients were maintained on daily antiplatelet therapy.

Patient age ranged from 45 to 76 years (average 63 years). Four patients were men and two were women. Angiography revealed greater than $95 \%$ stenosis in five patients and greater than $70 \%$ stenosis in one. Three patients had complete occlusion of the contralateral VA; in one other, the VA supplied only the posterior inferior cerebellar artery; and the remaining two patients had VAs with greater than 70\% stenosis. Ten stents were placed in six patients for five VA origin lesions and one distal VA stenosis. A VA dissection occurring poststenting was treated by placement of three additional stents. One patient had transient double vision. All had resolution of their presenting symptoms. Follow up ranged from 1 to 24 months (average 8.4 months). Angiograms obtained in four patients at least 3 months postprocedure have revealed stent patency in all cases without evidence of restenosis.

Vertebral artery stent placement can be safely performed and is a viable treatment option for carefully selected patients with vertebrobasilar insufficiency.

Key Words * endovascular * stent * vertebral artery * vertebrobasilar insufficiency

Vertebrobasilar (VB) insufficiency and transient ischemic attacks may be harbingers of significant 
morbidity and mortality, preceding brainstem infarction in up to $50 \%$ of patients.[3,24] Medical management includes both antiplatelet and anticoagulation therapies. However, in spite of maximum medical therapy, many patients exhibit refractory symptoms that necessitate revascularization procedures. $[4,5,9,14,19]$ The combined rates of perioperative morbidity, mortality, and graft/anastomosis occlusion for surgical bypass procedures range from 11 to 25\%.[14,21] Previously, primary angioplasty had been attempted in a limited number of symptomatic patients, resulting in various degrees of success associated with combined morbidity and mortality rates as high as 50\%.[10] Advances in catheter technology and clinical management of patients with VB disease has resulted in significantly improved access to VB lesions. We present our preliminary clinical experience using stent placement for symptomatic vertebral artery (VA) disease.

\section{CLINICAL MATERIAL AND METHODS}

From 1995 to 1998, six patients, in whom symptoms of VB insufficiency were refractory to medical management, underwent VA stenting. Failed medical management was defined as recurrent, persistent symptoms in spite of active antiplatelet and/or anticoagulation therapies. Symptoms of VB insufficiency were defined as those typically referable to the posterior fossa circulation, such as bilateral motor or sensory symptoms, diplopia, dysarthria, gait ataxia, dysmetria, homonymous hemianopsia, and drop attacks.[17,27] Patient age ranged from 45 to 76 years (average 63 years). Four patients were men and two were women. All patients were receiving combined antiplatelet therapy (aspirin and another antiplatelet medication) or had been started on a course of anticoagulation therapy at the time of initial evaluation by the neurosurgical service. All patients underwent outpatient diagnostic four-vessel transfemoral cerebral angiography by means of the Seldinger technique.[18] Following appropriate medical evaluation, patients were placed on ticlopidine and aspirin for 72 hours before hospital admission. On the day of surgery, all patients were premedicated with nimodipine, midazolam, ticlopidine, aspirin, and dexamethasone.

All patients received anticoagulation therapy consisting of intravenously administered heparin during the procedure. Anticoagulation status was monitored by activated clotting time measurements obtained every 30 to 45 minutes. A femoral introducer sheath was placed in the femoral artery by using the Seldinger technique and advanced to the innominate artery. A guidewire was placed across the lesion followed by placement of a microcatheter for urokinase infusion (150,000 U). If an initial infusion of urokinase resulted in angiographic changes in vessel morphology, the lesion was assumed to contain thrombus and an additional 100,000 $\mathrm{U}$ of urokinase were infused. Prior to stent placement in two cases, balloon angioplasty was performed using a low-profile balloon. Primary stent placement was performed in the remaining four patients. In each case, the stent was placed over the guidewire and across the stenotic lesion. Various stent types were utilized: the AVE, the Palmaz, and the Multilink stents. Stents were deployed at 8 to $10 \mathrm{~atm}$ pressure.

In two patients, severe ectasia of the innominate and subclavian vessels prevented navigation of guidewires or catheters to the VA origin. In these cases, the following transradial arterial approach was used: an Allen test was performed to verify ulnar artery collateral flow in the hand. After induction of local anesthesia applying the Seldinger technique, a No. 6 French sheath was introduced into the radial artery. To allay induced spasm, a mixture of heparin $\left(5000 \mathrm{U} / \mathrm{cm}^{3}\right)$, verapamil $(2.5 \mathrm{mg})$, nitroglycerin $\left(400 \mathrm{ug} / \mathrm{cm}^{3}, 0.25 \mathrm{~cm}^{3}\right)$, and lidocaine $\left(2 \% 1.0 \mathrm{~cm}^{3}\right)$ was infused through the introducer system. A microguidewire was positioned across the VA lesion followed by placement of a microcatheter. Following angiographic verification of the guidewire location, the microcatheter was removed, 
angioplasty was performed (as necessary), and a stent was placed across the lesion. After positioning the balloon catheter-stent system, the balloon was inflated to between 8 and $10 \mathrm{~atm}$ for stent deployment.

\section{Sources of Supplies and Equipment}

The guidewire (All-Star) and one stent (Multilink) were obtained from ASC (Temecula, CA); the microcatheter (Rapid Transit) from Cordis (Miami Lakes, FL); the low-profile balloon (Ranger) from SCIMED (Natick, MA); the Palmaz stent from Johnson \& Johnson (Warren, NJ); and the AVE stent from Arteriovascular Engineering (Santa Rosa, CA).

\section{RESULTS}

Angiography revealed more than $95 \%$ stenosis in five patients and more than $70 \%$ stenosis in one. Evaluation of the contralateral VAs revealed complete occlusion of the VA in three patients; one VA supplied only the posterior inferior cerebellar artery in one patient; and in the remaining two patients, more than $70 \%$ stenosis. Five of six patients had greater than $60 \%$ stenosis in at least one carotid artery. Presenting symptoms, comorbidities, and relevant procedures are summarized in Table 1.

\begin{tabular}{|c|c|}
\hline \multicolumn{2}{|c|}{$\begin{array}{c}\text { TABLE } 1 \\
\text { RELEYANT SYMPTOMS AND MED CAL HISTORY IN SIX } \\
\text { PATIENTS WITH YB INSUFFICIENCY }\end{array}$} \\
\hline Characteristic & No. of Patierts \\
\hline Elurred vision & 4 \\
\hline $\begin{array}{l}\text { nonlateralized iertigo } \\
\text { didopia. }\end{array}$ & $\frac{3}{2}$ \\
\hline bilat motor or sensory sym ptom s & 2 \\
\hline gait ataxia. & 1 \\
\hline nonisolated dro $p$ attacks & 1 \\
\hline dysmetria. & 1 \\
\hline associated carotid disease & 5 \\
\hline history of transient ischemic attack & 4 \\
\hline hypertension & 4 \\
\hline coronary artery disease & 3 \\
\hline prior ceretrovascular accident & 3 \\
\hline prior carotid endarterectom y & 3 \\
\hline prior coronary artery bypass graft & 2 \\
\hline diabetes & 1 \\
\hline
\end{tabular}

Ten stents were placed in six patients for five proximal VA lesions at the origin and one distal VA stenosis. A VA dissection that occurred poststenting was treated by the placement of three additional stents. The average hospital stay following stent placement was 4.5 days. All patients were admitted to the neurosurgical intensive care unit after the procedure. One transient neurological event occurred (transient double vision that resolved within several hours). There was no permanent morbidity and no death in this subgroup of patients. All patients had resolution of their presenting symptoms. Follow up ranged from 1 to 24 months for an average of 8.4 months. Angiograms obtained in four patients at least 3 months postprocedure have revealed stent patency in all cases. The remaining two patients are scheduled for follow-up angiography in the near future.

\section{ILLUSTRATIVE CASES}

\section{Case 1}


This 76-year-old woman had a history of previous bilateral carotid endarterectomy and coronary artery bypass surgery. She presented with diplopia and positional blurring of her vision. Diagnostic angiography revealed a left VA occlusion, recurrent bilateral carotid stenosis of 50 to $60 \%$, and a right VA origin stenosis of more than $95 \%$. She was started on a course of aspirin and ticlopidine but continued to experience symptoms of VB insufficiency more than 3 months later. She was referred for vertebral stenting. Transfemoral angioplasty followed by stenting with a Palmaz stent was performed without complication (Fig. 1). The patient's symptoms resolved postoperatively, and she continues to remain symptom free. Follow-up angiography revealed a patent VA without evidence of restenosis.

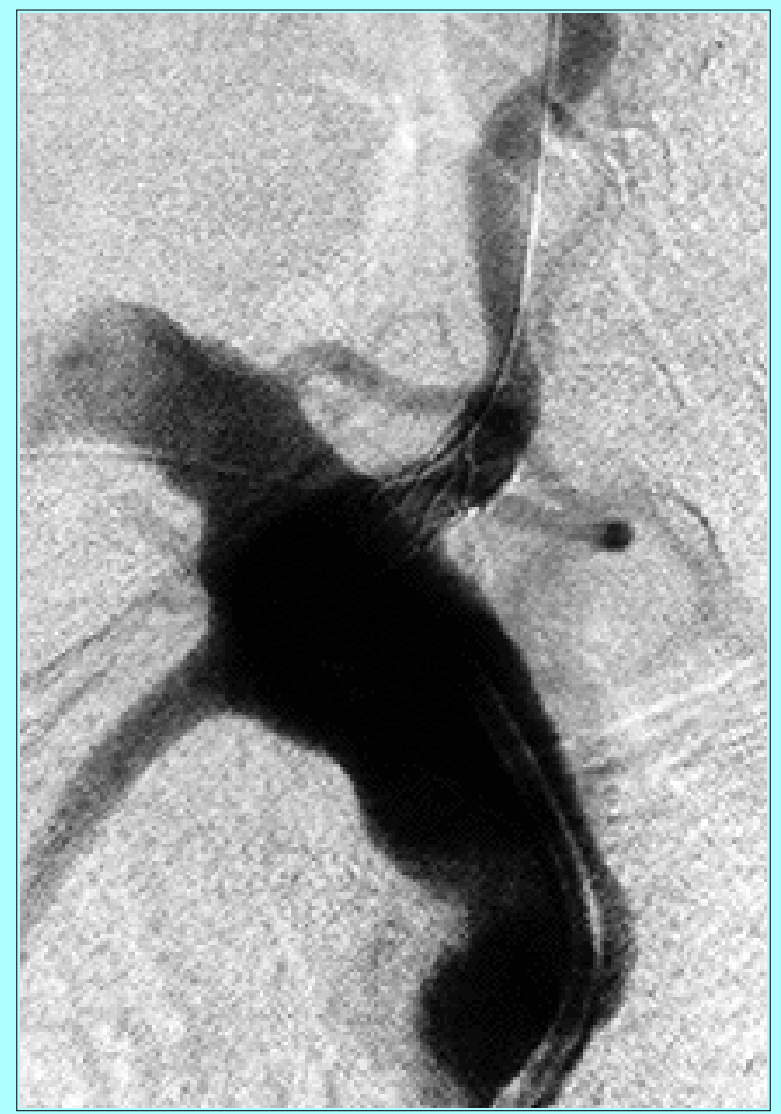

Fig. 1. Case 1. Angiogram showing stent with guidewire in place following deployment at the right VA origin. The stent protrudes slightly into the subclavian artery to prevent ostial hyperplasia and restenosis.

\section{Case 2}

This 49-year-old man had a history of hypertension, previous carotid endarterectomy, and hyperlipidemia. He presented with episodic severe nausea, emesis, diplopia, and nonlateralized vertigo. He was started on a course of antiplatelet therapy and aspirin daily without resolution of his symptoms. Diagnostic angiography revealed a 95\% stenosis of the right VA with multiple vessel irregularities (Fig. 2 left). The left VA was occluded. A transfemoral artery approach was used for access to the VA origin followed by urokinase infusion, angioplasty, and placement of two stents to reconstruct the arterial lumen (Fig. 2 right). The patient's symptoms have subsequently resolved, and he continues to remain symptom free. Follow-up angiography showed continued patency without instent stenosis (MS II/AVE; Arterial Vascular Engineering, Santa Rosa, CA). 


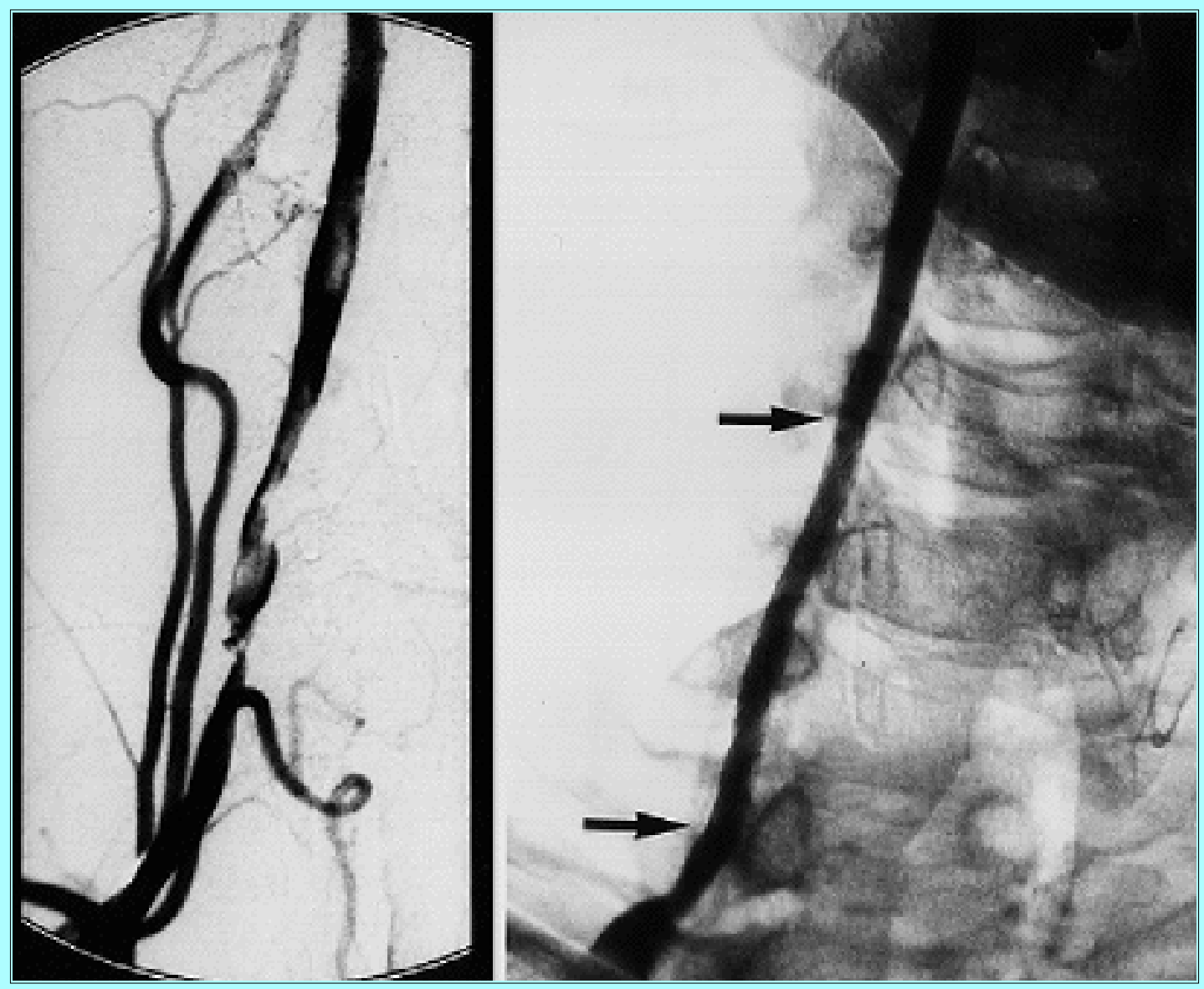

Fig. 2. Case 2. Left: A right VA angiogram showing severe atherosclerotic stenosis. There are multiple intraluminal filling defects, possibly representing thrombus. Following urokinase infusion and angioplasty, the arterial lumen was reconstructed with two MS II stents in tandem. Right: Angiogram showing the final result after reconstitution of the VA lumen. The arrows delineate the stent.

\section{DISCUSSION}

The extracranial VAs are a common site of stenosis and occlusion, with VB ischemic stroke accounting for up to $20 \%$ of all ischemic strokes.[3,26] Embolism from distant sites accounts for approximately 40 to $50 \%$ of these strokes, with the remainder secondary to atherosclerotic occlusive disease.[6,28] Symptomatic VB atherosclerotic occlusive disease can be associated with significant morbidity and mortality rates in up to $50 \%$ of patients.[3,24] Additionally, extra- and intracranial atherosclerotic disease is a significant predictor of extensive systemic disease and especially coronary artery disease.[15] Patients are at increased risk for myocardial infarction, sudden death, and stroke.[7]

The use of anticoagulants for VB ischemic symptoms has been a standard therapy beginning with the report of Millikan, et al.,[16] in which the mortality rate declined $43 \%$ in patients with VB insufficiency treated with intravenously administered anticoagulants. Although many patients benefit from anticoagulant and antiplatelet treatments, a subset remains refractory to these therapies and has persistent symptoms. Advances in microsurgery have resulted in a number of procedures designed to repair or bypass the diseased vessels. Such procedures have typically been reserved for patients with severe disease in whom all other therapies have failed.[1,2,4,14,19,22] Relative to the anterior cerebral circulation, bypass procedures do not provide greater protection against future stroke than aspirin alone,[11] and there have been no prospective randomized trials comparing posterior circulation bypass 
procedures to medical therapy.

Early results of percutaneous transluminal angioplasty were no more encouraging than surgical or medical therapy. Reserved for seriously ill, symptomatic patients, complication rates from angioplasty ranged from 12 to $33 \%$.[8,13,23] Complications from angioplasty increase as angioplasty progresses in a rostral direction. Touho [25] has reported a $38.5 \%$ restenosis rate for intracranial vessels of the anterior circulation. Terada, et al.,[23] have reported one restenosis following angioplasty in 12 patients who underwent VB angioplasty; however, the immediate complication rate was $33 \%$.

Vertebral artery stenting has been performed in a limited number of cases. Feldman, et al.,[12] have reported a case of severe bilateral VA origin stenosis treated with bilateral stenting. The patient remained asymptomatic 8 months following stent placement. The technical feasibility of VA stenting has been shown by Storey, et al.,[20] who reported three patients in whom symptomatic restenosis occurred within 3 months of VA angioplasty. One patient had symptoms of VB insufficiency, whereas the others had anterior circulation ischemia with diminished supply from the VAs. Stents were placed with resolution of symptoms in the patient with primary VB symptoms, and the remaining two patients underwent an extracranial-intracranial bypass procedure with resolution of their symptoms.

The current study reports on six patients, all with medically refractory symptoms of VB disease, in whom stenting resulted in resolution of their symptoms. Stenting of the VA can be safely performed with satisfactory clinical results. In cases of VA origin stenosis, we prefer to place the stent across the lesion so that a small portion protrudes into the subclavian artery. This prevents ostial restenosis from intimal hyperplasia. Stenting of the VA is potentially more applicable to clinical practice than in the internal carotid artery. Relative to the internal carotid artery, the surgical options for extracranial VA occlusive disease are technically demanding and of no demonstrated benefit. The use of VA stents for atherosclerotic occlusive disease should be considered a viable treatment alternative to open surgical approaches in select patients. Stenting may lead to lower restenosis rates compared with transluminal angioplasty and may be indicated in cases of restenosis following transluminal angioplasty.

\section{CONCLUSIONS}

Six patients underwent stenting of the VA for symptomatic VA occlusive disease. All patients experienced resolution of their symptoms. Vertebral artery stenting is technically feasible and can be performed in select patients. Long-term clinical and angiographic follow-up examination of these patients is mandatory to assess the long-term durability and efficacy of this appealing approach.

\section{References}

1. Allen GS, Cohen RJ, Preziosi TJ: Microsurgical endarterectomy of the intracranial vertebral artery for vertebrobasilar transient ischemic attacks. Neurosurgery 8:56-59, 1981

2. Ausman JI, Diaz FG, de los Reyes RA, et al: Posterior circulation revascularization. Superficial temporal to superior cerebellar artery anastomosis. J Neurosurg 56:766-776, 1982

3. Ausman JI, Shrontz CE, Pearch JE, et al: Vertebrobasilar insufficiency. Arch Neurol 42:803-808, 1985

4. Berguer R, Morasch MD, Kline RA: A review of 100 consecutive reconstructions of the distal vertebral artery for embolic and hemodynamic disease. J Vasc Surg 27:852-859, 1998 
5. Brink B: Approach to the second segment of the VAs, in Berguer R, Bauer RB (eds): Vertebrobasilar Arterial Occlusive Disease. Medical and Surgical Management. New York: Raven Press, 1984, pp 257-264

\section{Caplan LR: Posterior Circulation Disease: Clinical Findings, Diagnosis, and Management.} Cambridge, Mass: Blackwell Scientific, 1996

7. Chimowitz MI, Kokkinos J, Strong J, et al: The Warfarin-Aspirin Symptomatic Intracranial Disease Study. Neurology 45:1488-1493, 1995

8. Clark WM, Barnwell SL, Nesbit G, et al: Safety and efficacy of percutaneous transluminal angioplasty for intracranial atherosclerotic stenosis. Stroke 26:1200-1204, 1995

9. Diaz FG, Ausman JI, Shrontz C, et al: Surgical correction of lesions affecting the second portion of the vertebral artery. Neurosurgery 19:93-100, 1986

10. Dorros G, Cohn JM, Palmer LE: Stent deployment resolves a petrous carotid artery angioplasty dissection. AJNR 19:392-394, 1998

11. EC/IC Bypass Study Group: Failure of extracranial-intracranial arterial bypass to reduce the risk of ischemic stroke. Results of an international randomized trial. N Engl J Med 313:1191-1200, 1985

12. Feldman RL, Rubin JJ, Kuykendall RC: Use of coronary Palmaz-Schatz stent in the percutaneous treatment of vertebral artery stenoses. Cathet Cardiovasc Diagn 38:312-315, 1996

13. Higashida RT, Tsai FY, Halbach VV, et al: Cerebral percutaneous transluminal angioplasty. J Heart Dis Stroke 2:497-502, 1993

14. Hopkins LN, Martin NA, Hadley MN, et al: Vertebrobasilar insufficiency. Part 2: Microsurgical treatment of intracranial vertebrobasilar disease. J Neurosurg 66:662-674, 1987

15. Marzewski DJ, Furlan AJ, Louis P, et al: Intracranial internal carotid artery stenosis: longterm prognosis. Stroke 13:821-824, 1982

16. Millikan CH, Siekert RG, Shick RM: Studies in cerebrovascular disease: III. The use of anticoagulant drugs in the treatment of insufficiency or thrombosis within the basilar arterial system. Mayo Clin Proc 30:116-126, 1955

17. Oas JG, Baloh RW: Vertigo and the anterior inferior cerebellar artery syndrome. Neurology 42:2274-2279, 1992

18. Seldinger SI: Catheter replacement of the needle in percutaneous angiography: a new technique. Acta Radiol 39:368-376, 1953

19. Spetzler RF, Hadley MN, Martin NA, et al: Vertebrobasilar insufficiency. Part 1: Microsurgical treatment of extracranial vertebrobasilar disease. J Neurosurg 66:648-661, 1987

20. Storey GS, Marks MP, Dake M, et al:Vertebral artery stenting following percutaneous transluminal angioplasty. Technical note. J Neurosurg 84:883-887, 1996

21. Sundt TM Jr, Piepgras DG: Extracranial to intracranial bypass grafting: posterior circulation, in Wilkins RH, Rengachary SS (eds): Neurosurgery. New York: McGraw-Hill, 1985, Vol 2, pp 1281-1292 
22. Sundt TM Jr, Piepgras DG: Occipital to posterior inferior cerebellar artery bypass surgery. J Neurosurg 48:916-928, 1978

23. Terada T, Higashida RT, Halbach VV, et al: Transluminal angioplasty for arteriosclerotic disease of the distal vertebral and basilar arteries. J Neurol Neurosurg Psychiatry 60:377-381, 1996

24. Thompson JR, Simmons CR, Hasso AN, et al: Occlusion of the intradural vertebrobasilar artery. Neuroradiology 14:219-229, 1978

25. Touho H: Percutaneous transluminal angioplasty in the treatment of atherosclerotic disease of the anterior circulation and hemodynamic evaluation. J Neurosurg 82:953-960, 1995

26. Turney TM, Garraway WM, Whisnant JP: The natural history of hemispheric and brainstem infarction in Rochester, Minnesota. Stroke 15:790-794, 1984

27. Whisnant JP, Cartlidge NE, Elveback LR: Carotid and vertebral-basilar transient ischemic attacks: effect of anticoagulants, hypertension, and cardiac disorders on survival and stroke occurrence--a population study. Ann Neurol 3:107-115, 1978

28. Wityk, R, Chang HM, Rosengart A, et al: Proximal extracranial vertebral artery disease in the New England Medical Center Posterior Circulation Registry. Arch Neurol 55:470-478, 1998

Manuscript received August 21, 1998.

Accepted in final form September 3, 1998.

Research funding and equipment for this study were supplied by Arterial Vascular Engineering, Boston Scientific, and Cordis Endovascular.

Address reprint requests to: Richard D. Fessler, M.D., Department of Neurosurgery, 3 Gates Circle, Buffalo, New York 14209-1194. email: fessler@ neurosurg.wayne.edu. 